\title{
Transsphenoidal Surgery for Secreting Pituitary Microadenomas: Results with Intraoperative Application of Absolute Alcohol
}

\author{
Mario F. Fraioli ${ }^{*}$, Andrea Paganoํ, Giuseppe Giovinazzo ${ }^{2}$, Pierpaolo Lunardi ${ }^{1}$, \\ Bernardo Fraioli ${ }^{3}$ \\ ${ }^{1}$ Department of Neurosurgery, University of Rome Tor Vergata, Rome, Italy \\ ${ }^{2}$ Department of Radiotherapy, IFO Regina Elena of Rome, Rome, Italy \\ ${ }^{3}$ Department of Radiology and Radiotherapy, CIRAD Villa Benedetta of Rome, Rome, Italy \\ Email: mff77@libero.it
}

Received 3 July 2014; revised 4 August 2014; accepted 5 September 2014

Copyright (C) 2014 by authors and Scientific Research Publishing Inc.

This work is licensed under the Creative Commons Attribution International License (CC BY). http://creativecommons.org/licenses/by/4.0/

c) (i) Open Access

\section{Abstract}

Background: Pituitary adenomas represent a quite frequent neurosurgical disease. Secreting pituitary adenomas are represented by PRL, GH, ACTH and TSH tumours; the rate of postoperative hormonal recurrence is not ineligible. Methods: We present 106 patients affected by secreting pituitary microadenomas operated through transsphenoidal approach from 1998 through to 2008; in 54 (group 1) patients, intraoperative absolute alcohol was applied, while in the other 52 (group 2) it was not employed. The indications and the intraoperative technique of absolute alcohol application are presented. Hormonal recurrence was treated by hypofractionated stereotactic radiotherapy and/or medical therapy. Results: Postoperative hormonal and clinical remission was achieved in 50 and 47 patients respectively of group one and group two. At the first follow-up control, after 3 months from surgery, no patient of both groups presented hormonal/clinical recurrence. Six months after surgery, no patient of group one presented hormonal recurrence, while two patients of group 2 presented hormonal recurrence. After 2 years from surgery, two patients of group 1 and 4 patients of group 2 presented hormonal recurrence. Three years after operation, hormonal hypersecretion recurred in three patients of group one and in six patients of group 2. At 5 years follow-up, six patients of group one and 8 of group two presented hormonal recurrence. Conclusions: Intraoperative application of absolute alcohol, in selected cases, resulted useful to achieve better results in secreting pituitary microadenomas concerning both postoperative hormonal recurrence and hormonal persistence.

\footnotetext{
${ }^{*}$ Corresponding author.
} 


\section{Keywords}

\section{Pituitary Microadenoma, Absolute Alcohol, Hormonal Recurrence, Transsphenoidal Surgery}

\section{Introduction}

Pituitary adenomas represent a quite frequent neurosurgical disease, encountered in about $16.7 \%$ of people (14.4\% in autopsy studies and $22.5 \%$ in radiologic studies) [1]. Secreting pituitary microadenomas are a subgroup and are represented, in order of decreasing frequency, by PRL, GH, ACTH and TSH tumours. While for microprolactinomas, the therapy of choice is represented by medical therapy (cabergoline/bromocriptine) and surgery/radiosurgery is reserved for patients resistant or intolerant to the above mentioned drugs. For the other secreting lines, the first choice is transsphenoidal surgery, and medical therapy (somatostatin analogues and steroidogenesis inhibitors for GH and ACTH secreting adenomas respectively) and radiotherapy are reserved for recurrence/hormonal persistence [2]-[4]. Although technologic improvements in transsphenoidal approaches during the last decades (microscope, endoscope, neuronavigator, intraoperative MRI), the rate of hormonal recurrence is not ineligible [2] [5]. For this reason, postoperative stereotactic radiotherapy and medical therapy play a significant role for the treatment of secreting pituitary microadenomas [6]-[10].

We present 2 groups of secreting microadenomas operated with and without intraoperative use of absolute alcohol respectively, to evaluate the different rate of postoperative hormonal remission and hormonal recurrence at distance. The indication and the intraoperative technique of absolute alcohol application are presented. Only few authors describe intraoperative application of absolute alcohol in pituitary adenomas, but its role in reducing or avoiding hormonal recurrence in secreting microadenomas has not been yet evaluated, to our knowledge [11]-[15].

\section{Materials and Methods}

A total of 106 patients (64 female, 42 male) affected by secreting microadenomas were considered. Patients age was between 22 and 62 years (average 47.4). Patients affected by microadenoma invading cavernous sinus were not considered in the study, because our therapeutic strategy in these cases is represented by surgery for the intrasellar part of the adenoma and postoperative stereotactic radiotherapy for the intracavernous part of tumour. All were operated through transsphenoidal surgery from 1998 through to 2008; in 54 (group 1) intraoperative absolute alcohol was applied, while in the other 52 (group 2) it was not employed (Table 1). Preoperative diagnosis was assessed by hormonal studies which revealed hormonal hypersecretion, by clinical signs and symptoms related to hormonal hypersecretion, and by 1.5 tesla MRI which showed in all cases a clear microadenoma and also a delay of enhancement, at the dynamic sequence, of a portion less than $10 \mathrm{~mm}$ into the context of the pituitary gland (Figure 1); pituitary stalk deviation was present in $79 \%$ of microadenomas. Postoperative controls were assessed by 1.5 tesla MRI performed after 6 months and then once at year for 5 years, and by hormonal exams performed in the immediate postoperative period (5 - 10 days), after three, six months and afterwards once at year. In our opinion and experience, postoperative MRI after transsphenoidal surgery for microadenomas plays a minor role than postoperative blood hormone levels to evaluate the results; so that postoperative evaluations and indications were mainly performed on the basis of blood hormone levels. Magnetic resonance image was important in patients with postoperative hormonal persistence or hormonal recurrence who were submitted to stereotactic radiotherapy.

Table 1. Population of the study: 106 patients affected by secreting pituitary microadenomas.

\begin{tabular}{ccc}
\hline & Group 1 (intraoperative alcohol application) & Group 2 (no intraoperative alcohol application) \\
\hline GH & 28 & 29 \\
PRL & 14 & 13 \\
ACTH & 12 & 10 \\
\hline
\end{tabular}




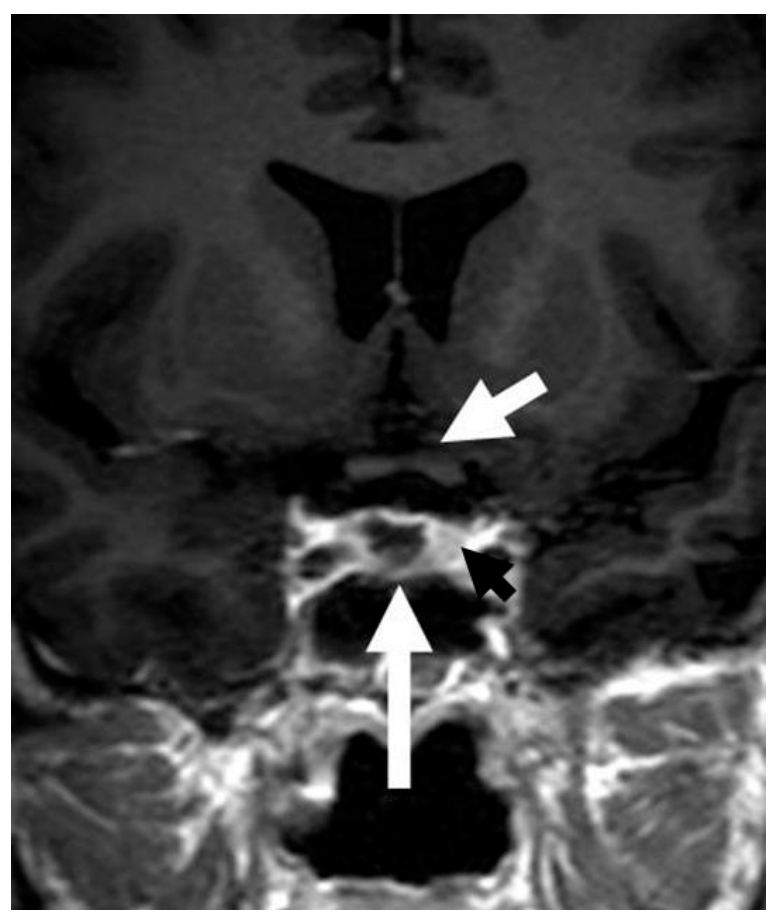

Figure 1. Post-contrast T1 coronal MR image showing a microadenoma in the median portion and in the right side of the pituitary gland. Long white arrow: microadenoma. Short white arrow: optic chiasm. Black arrow: left portion of pituitary gland.

Fifty-seven patients were affected by GH secreting, twenty-seven by PRL-secreting and the last 22 by ACTHsecreting microadenomas (Table 1). All the microprolactinomas had been previously treated by medical therapy, and they were addressed to the neurosurgeon because of medical therapy intolerance or drug resistance.

\section{Surgical Technique}

All the patients were operated through a transsphenoidal microsurgical approach, endoscope-assisted from 2000. Operation was performed through one nostril, by a submucosal access to the anterior wall of sphenoidal plane. Then, after opening of the sella turcica, dura mater was exposed (Figure 2) and then opened; in all patients a clear microadenoma was exposed and removed by dissection and aspiration, achieving a micro surgical cave into the context of the pituitary gland which was spared (Figure 3). In all cases, the limits of the surgical cave were coagulated by dedicated bipolar. Starting from 2003, in all patients affected by secreting microadenoma without evidence of intraoperative CSF leak, we used to apply intraoperative absolute alcohol at the end of tumor removal. So that in patients of group one, all operated from 2003 through to 2008, intraoperative application of absolute alcohol was performed, as reported: at the end of microadenoma removal, in all cases a surgical cave was evident, and a micro-surgical patty $(0.5 \times 0.5 \mathrm{~cm})$ soaked in absolute alcohol was applied into the micro-surgical cave and kept in situ for about 2 minutes (Figure 4); this operation was repeated 3 - 4 times. In patients of group two, operated from 1998 through to 2003 and in 2 cases in 2007, intraoperative absolute alcohol was not applied. In the last 2 cases of group two, intraoperative application of absolute alcohol was not performed because of intraoperative CSF leak, to don't run the risks of alcohol diffusion into the subarachnoid space.

\section{Results}

No deaths and no neurologic deficits occurred after surgery. Concerning the endocrinology status, during an average follow-up period of 9, 4 years, no pituitary hormonal deficit occurred in any group. Moreover, four pa- 


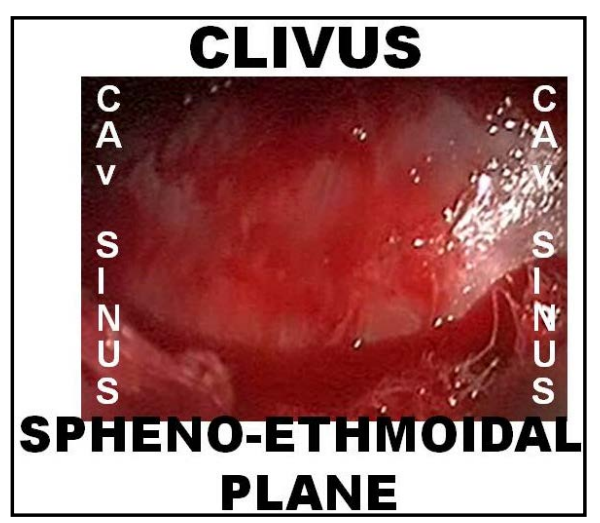

Figure 2. Microsurgical view of exposition of pituitary and peritumoral dura mater.
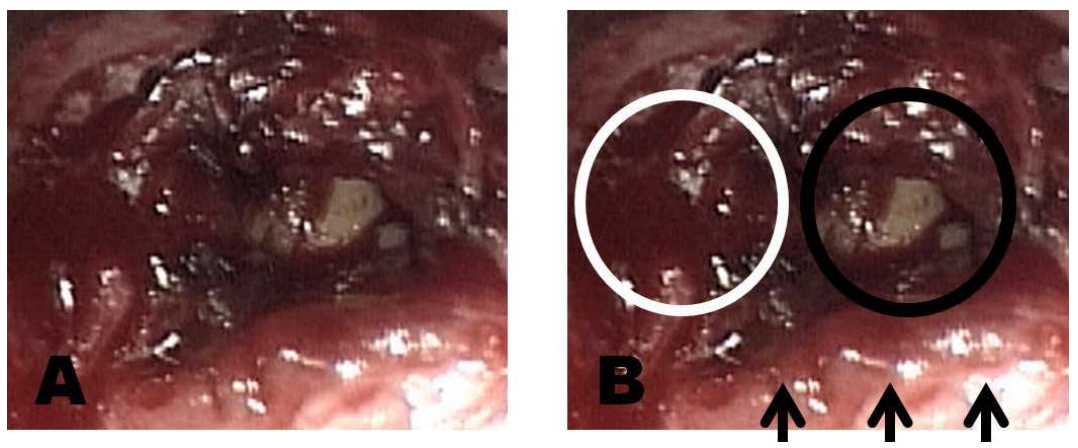

Figure 3. (A) Microsurgical view of the operative field after removal of microadenoma. (B) The white circle indicates the left side of the pituitary gland; the black circle indicates the operative microsurgical field in the right portion of the pituitary gland; the short black arrows indicate the superior part of the dura mater over the suprasellar cistern.

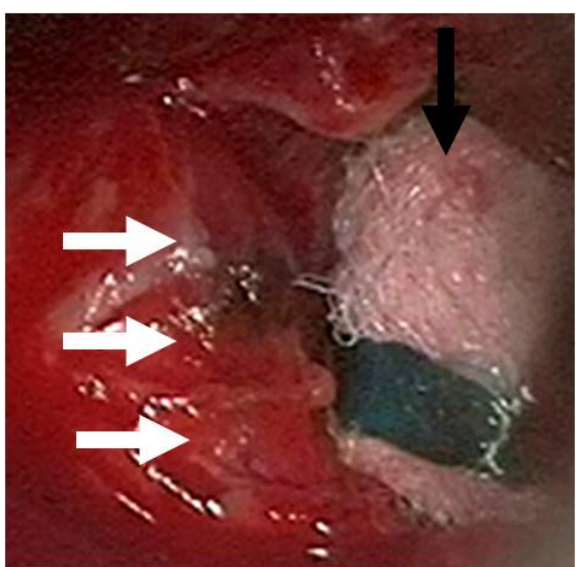

Figure 4. A patty (black arrow) soaked in absolute alcohol has been placed into the microsurgical operative field; the white short arrows indicate the left side of the pituitary gland.

tients of group one and five of group two presented transitory diabetes insipidus (during the first three postoperative days) treated by desmopressin. No statistical significant difference was observed in group one and group two regarding postoperative diabetes insipidus.

At operative view (microscopic/endoscopic), according to operator's opinion, total removal was accomplished in all patients. 


\subsection{Postoperative Hormonal Remission and Recurrence}

Postoperative hormonal and clinical remission was achieved in 50 and 47 patients respectively of group one and group two. However, in the remaining 9 patients affected respectively by ACTH, GH and PRL microadenoma in four, two and three cases respectively, a clear evidence of hormonal and clinical improvement was achieved.

At the first follow-up control, after 3 months from surgery, no patient presented hormonal/clinical recurrence.

At the second follow-up control, six months after surgery, no patient of group one presented hormonal recurrence, while two patients of group 2 presented hormonal recurrence (ACTH and PRL respectively).

After 2 years from surgery, two patients of group 1 (1 PRL and $1 \mathrm{GH}$ ), and 4 patients of group 2 (1 PRL and 3 $\mathrm{GH})$ presented hormonal recurrence.

Three years after operation, hormonal hypersecretion recurred in three patients of group one (1 ACTH, 1 PRL, $1 \mathrm{GH}$ ) and in six patients of group 2 (1 ACTH, 2 PRL, $3 \mathrm{GH})$.

At 5 years follow-up, five patients of group one presented ACTH and GH hormonal recurrence in one and two cases respectively. Concerning group two, ACTH, PRL and GH hypersecretion recurred in one, one and two patients respectively.

\subsection{Treatment of Postoperative Persistent Hormonal Hypersecretion and Treatment of Recurrences}

Out of the nine patients (belonging to group 1 and group 2 in 4 and 5 cases respectively) with postoperative hormonal persistence, they were submitted to pituitary MRI after 15 days from surgery, but a clear evidence of postoperative tumor remnant was not detected in any case. However, in 6 cases they were submitted to postoperative hypofractionated stereotactic radiotherapy: the target was the microsurgical cave identified at fused MRI and CT images, the patients were immobilized by a thermoplastic mask with bite, and the stereotactic coordinated were identified through a relocatable sterotactic frame; the radiation dose was delivered through a dedicated linear accelerator for a total dose of $40 \mathrm{~Gy}$ in 10 fractions of $4 \mathrm{~Gy}$, twice a week. In the last three patients, affected by PRL secreting microadenomas, treatment with cabergoline was performed at a minor dose than the preoperative one ( $0.5 \mathrm{mg}$ a week to control PRL levels).

The 2 patients of group 2 affected by hormonal recurrence (ACTH and PRL) after 6 months from surgery, were treated by stereotactic radiotherapy and by cabergoline respectively.

The 2 patients affected by recurrence of PRL secretion after 2 years of follow-up, were treated by cabergoline, while the three patients affected by GH recurrence were treated by stereotactic radiotherapy with target centered on the surgical cave.

The 6 patients affected by recurrent GH and ACTH microadenomas after 3 years follow-up, were submitted to HSRT; the 3 patients affected by PRL recurrent microadenomas were treated by cabergoline in two cases and by HSRT in the other one because of intolerance to cabergoline.

\subsection{Analysis of Results}

Considering rate of recurrence according to the type of hypersecretion, during the same follow-up period of 5 years for both groups, patients of group 2 (no application of intraoperative absolute alcohol) presented a major rate of recurrence than patients of group one (application of intraoperative absolute alcohol), as showed in Table 2: ACTH secreting microadenoma presented a rate of recurrence of $16.6 \%$ and $30 \%$ in group one and group two respectively; PRL microadenomas presented a rate of recurrence of $14.3 \%$ and $38.4 \%$ in group one and group two respectively; finally, rate of recurrence in GH secreting microadenomas was $14.3 \%$ and $27.5 \%$ in group one and group two respectively.

Moreover, considering the follow-up steps of 6 months, two, three and five years, patients of group 2 presented in all cases a major rate of recurrence (Table 2).

\section{Discussion}

The effects of alcohol on the pituitary gland are known by many years, and in the past pituitary block by alcoholization was used to treat malignant tumours as thyroid and prostate cancer or to treat tumoral pain [16]-[19]; reported complications after pituitary alcoholization were represented by diabetes insipidus and visual disturbances [18]. Pituitary alcoholization was performed by injecting $1 \mathrm{ml}$ of absolute alcohol into the pituitary gland 
Table 2. Hormonal remission and recurrence at distance in 106 pituitary secreting microadenomas. Group 1 (54 patients): intraoperative application of absolute alcohol. Group 2 (52 patients): no intraoperative application of absolute alcohol.

\begin{tabular}{cccccccc}
\hline & $\begin{array}{c}\text { Postoperative } \\
\text { hormonal } \\
\text { remission }\end{array}$ & $\begin{array}{c}\text { Postoperative } \\
\text { hormonal } \\
\text { persistence }\end{array}$ & $\begin{array}{c}\text { Hormonal } \\
\text { recurrence } \\
\text { at 6 months }\end{array}$ & $\begin{array}{c}\text { Hormonal } \\
\text { recurrence } \\
\text { at 2 years }\end{array}$ & $\begin{array}{c}\text { Hormonal } \\
\text { recurrence } \\
\text { at 3 years }\end{array}$ & $\begin{array}{c}\text { Hormonal } \\
\text { recurrence } \\
\text { at 5 years }\end{array}$ & $\begin{array}{c}\text { Total hormonal } \\
\text { recurrence }\end{array}$ \\
\hline Group 1 ACTH & 11 & 1 & - & - & 1 & 1 & $2(16.6 \%)$ \\
Group 2 ACTH & 7 & 3 & 1 & - & 1 & 1 & $3(30 \%)$ \\
Group 1 PRL & 12 & 2 & - & 1 & 1 & - & $2(14.3 \%)$ \\
Group 2 PRL & 12 & 1 & 1 & 1 & 2 & 1 & $5(38.4 \%)$ \\
Group 1 GH & 27 & 1 & - & 1 & 1 & 2 & $4(14.3 \%)$ \\
Group 2 GH & 28 & 1 & - & 3 & 3 & 2 & $8(27.5 \%)$ \\
Group 1 & $50(92.6 \%)$ & $4(7.4 \%)$ & - & $2(4 \%)$ & $3(6 \%)$ & $3(6 \%)$ & $8(14.8 \%)$ \\
Group 2 & $47(90.3 \%)$ & $5(9.7 \%)$ & $2(4.2 \%)$ & $4(8.5 \%)$ & $6(11.5 \%)$ & $4(8.5 \%)$ & $15(28.8 \%)$ \\
\hline
\end{tabular}

through a needle inserted by a transsphenoidal approach [18]. On the basis of these known effects on the pituitary gland, few Authors used to apply absolute alcohol into the surgical cave after adenoma removal, but no Authors specifically analyzed the role of absolute alcohol in reducing the postoperative rate of hormonal persistence and hormonal recurrence in secreting pituitary microadenomas [11]-[15]. In our experience, we used to apply absolute alcohol into the operative field by a patty soaked in absolute alcohol, kept in situ for 1 - 2 minutes, repeating the operation $4-5$ times. By this way of application, we achieved a statistical significant difference concerning the rate of postoperative rate of recurrence $(\mathrm{p}<0.05)$ between group one (use of absolute alcohol) and group two (no use of absolute alcohol); concerning the rate of postoperative hormonal remission, no significant statistical difference was detected between the two groups (Table 2).

\subsection{Indications for Application of Absolute Alcohol}

In our experience, application of intraoperative absolute alcohol is indicated only in secreting microadenomas because, after surgical removal, the operative field is usually represented by a micro surgical cave into the context of the pituitary gland (Figure 2), and a microsurgical patty soaked in absolute alcohol can be applied without any contact with the suprasellar cisternal plane or the medial walls of cavernous sinuses. Moreover, its application is particularly indicated when the surgeon intends to perform a very conservative surgical approach, especially in young patients, without removing or damaging the pituitary tissue, and it is possible that micro fragments of adenoma are left in situ.

\subsection{Contraindications for Intraoperative Absolute Alcohol Application}

Absolute contraindication is the presence of intraoperative liquor leak because of damage to the suprasellar cistern; in these cases absolute alcohol could spread into the subarachnoid space with possible chemical meningitis. In our opinion, also in macroadenomas intraoperative absolute alcohol is contraindicated, because the operative field at the end of tumour removal is usually represented in these cases by the suprasellar cistern descent into the superior part of the operative field; the microsurgical patty drenched by absolute alcohol, applied into the surgical cave, could contact the suprasellar cistern and alcohol could be absorbed into the subarachnoid space with liquoral spreading, because suprasellar cistern could be thinner because of tumor infiltration or because of inveterate compression by the macroadenoma.

Moreover, application of absolute alcohol is useless, in our opinion, for secreting microadenomas with cavernous sinus infiltration, because for these cases our indication is to perform postoperative stereotactic radiotherapy, which however would have effect also on a possible intra-pituitary tumoral remnant.

\section{Conclusion}

Intraoperative application of absolute alcohol, in selected cases, resulted useful to achieve better results in transsphenoidal surgery for secreting pituitary microadenomas; in our experience, a minor rate of hormonal recur- 
rence at distance and a major rate of postoperative hormonal remission were achieved.

\section{References}

[1] Ezzat, S., Asa, S.L., Couldwell, W.T., Barr, C.E., Dodge, W.E., Vance, M.L. and McCutcheon, I.E. (2004) The Prevalence of Pituitary Adenomas: A Systematic Review. Cancer, 101, 613-619. http://dx.doi.org/10.1002/cncr.20412

[2] Kreutzer, J. and Fahlbusch, R. (2004) Diagnosis and Treatment of Pituitary Tumors. Current Opinion in Neurology, 17, 693-703. http://dx.doi.org/10.1097/00019052-200412000-00009

[3] Liu, J.K. and Couldwell, W.T. (2004) Contemporary Management of Prolactinomas. Neurosurgical Focus, 16, E2. http://dx.doi.org/10.3171/foc.2004.16.4.3

[4] Philippon, M., Castinettia, F. and Bruea, T. (2013) Cushing's Disease with Negative Imaging in Adults. Annales d'Endocrinologie (Paris), 74, S23-S32. http://dx.doi.org/10.1016/S0003-4266(13)70018-0

[5] Patil, C.G., Prevedello, D.M., Lad, S.P., Vance, M.L., Thorner, M.O., Katznelson, L. and Laws Jr., E.R. (2008) Late Recurrences of Cushing's Disease after Initial Successful Transsphenoidal Surgery. The Journal of Clinical Endocrinology and Metabolism, 93, 358-362. http://dx.doi.org/10.1210/jc.2007-2013

[6] Colao, A., Boscaro, M., Ferone, D. and Casanueva, F.F. (2014) Managing Cushing's Disease: The State of the Art. Endocrine.

[7] Ding, D., Starke, R.M. and Sheehan, J.P. (2013) Treatment Paradigms for Pituitary Adenomas: Defining the Roles of Radiosurgery and Radiation Therapy. Journal of Neuro-Oncology, 117, 445-457.

[8] Jallad, R.S. and Bronstein, M.D. (2013) The Place of Medical Treatment of Acromegaly: Current Status and Perspectives. Expert Opinion on Pharmacotherapy, 14, 1001-1015. http://dx.doi.org/10.1517/14656566.2013.784744

[9] Stapleton, C.J., Liu, C.Y. and Weiss, M.H. (2010) The Role of Stereotactic Radiosurgery in the Multimodal Management of Growth Hormone-Secreting Pituitary Adenomas. Neurosurg Focus, 29, E11.

[10] Wilson, P.J., Williams, J.R. and Smee, R.I. (2014) Cushing's Disease: A Single Centre's Experience Using the Linear Accelerator (LINAC) for Stereotactic Radiosurgery and Fractionated Stereotactic Radiotherapy. Journal of Clinical Neuroscience, 21, 100-106. http://dx.doi.org/10.1016/j.jocn.2013.04.007

[11] Amar, A.P., Couldwell, W.T., Chen, C.T. and Weiss, M.H. (2002) Predictive Value of Serum Prolactin Levels Measured Immediately after Transsphenoidal Surgery. Journal of Neurosurgery, 97, 307-314. http://dx.doi.org/10.3171/jns.2002.97.2.0307

[12] Chen, C.T., Amar, A.P., Choi, S., Singer, P., Couldwell, W.T. and Weiss, M.H. (2003) Transsphenoidal Microsurgical Treatment of Cushing Disease: Postoperative Assessment of Surgical Efficacy by Application of an Overnight Low-Dose Dexamethasone Suppression Test. Journal of Neurosurgery, 98, 967-973. http://dx.doi.org/10.3171/jns.2003.98.5.0967

[13] Ross, D. and Wilson, C.B. (1988) Results of Transsphenoidal Microsurgery for Growth Hormone-Secreting Pituitary Adenoma in a Series of 214 Patients. Journal of Neurosurgery, 68, 854-867. http://dx.doi.org/10.3171/jns.1988.68.6.0854

[14] Selman, W., Laws Jr., E.R., Scheithauer, B.W. and Carpente, S.M. (1986) The Occurrence of Dural Invasion in Pituitary Adenomas. Journal of Neurosurgery, 64, 402-407. http://dx.doi.org/10.3171/jns.1986.64.3.0402

[15] Wisławski, J., Kasperlik-Załuska, A.A., Jeske, W., Migdalska, B., Janik, J., Załuska, J. and Bonicki, W. (1985) Results of Neurosurgical Treatment by a Transsphenoidal Approach in 10 Patients with Nelson's Syndrome. Journal of Neurosurgery, 62, 68-71. http://dx.doi.org/10.3171/jns.1985.62.1.0068

[16] Greco, T. (1965) Alcoholization of the Hypophysis in Treatment of Malignant Tumors. Advantages of this Method and Conclusive Considerations. Ospedali d'Italia-Chirurgia, 12, 439-448.

[17] Greco, T., Sbaragli, F. and Mininni, D. (1965) Alcoholization of the Hypophysis in Thyroid Cancer. Ospedali d'Italia-Chirurgia, 12, 425-427.

[18] Lloyd, J.W., Rawlinson, W.A. and Evans, P.J. (1981) Selective Hypophysectomy for Metastatic Pain. A Review of Ethyl Alcohol Ablation of the Anteriorpituitary in a Regional Pain Relief Unit. British Journal of Anaesthesia, 53, 1129-1133. http://dx.doi.org/10.1093/bja/53.11.1129

[19] Sorrentino, F. (1965) Alcoholization of the Pituitary Gland in the Treatment of Prostatic Cancer. Urologia Internationalis, 19, 47-53. http://dx.doi.org/10.1159/000279269 
Scientific Research Publishing (SCIRP) is one of the largest Open Access journal publishers. It is currently publishing more than 200 open access, online, peer-reviewed journals covering a wide range of academic disciplines. SCIRP serves the worldwide academic communities and contributes to the progress and application of science with its publication.

Other selected journals from SCIRP are listed as below. Submit your manuscript to us via either submit@scirp.org or Online Submission Portal.
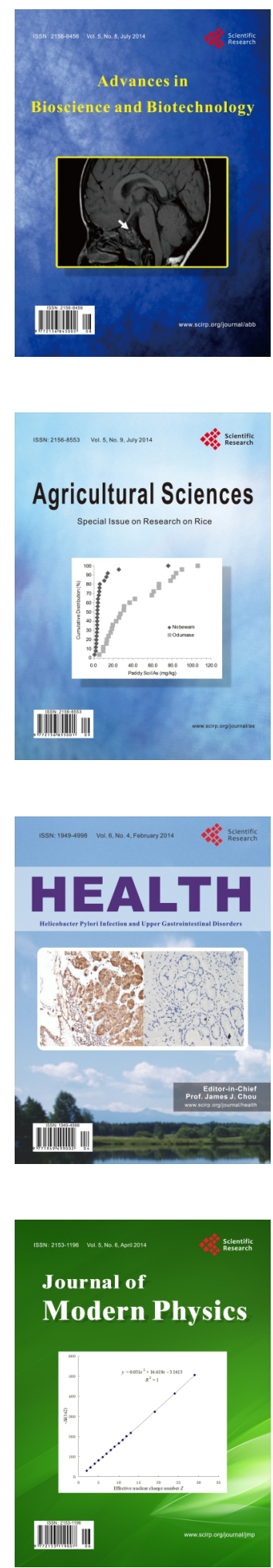
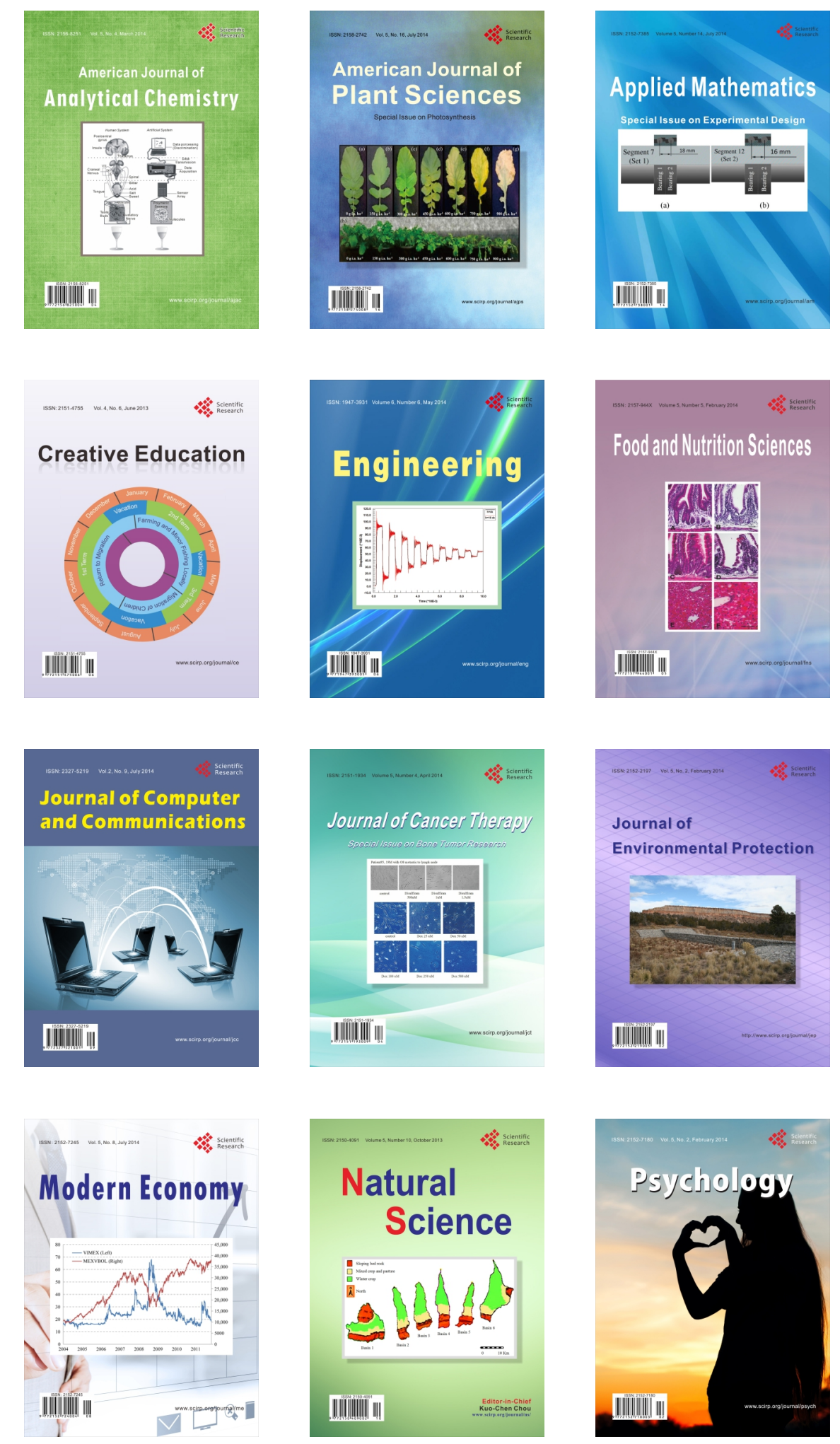